\title{
Enhancement of beta-catenin in cardiomyocytes suppresses survival protein expression but promotes apoptosis and fibrosis
}

James C. Lin ${ }^{1,2}$, Wei-Wen Kuo ${ }^{3}$, Rathinasamy Baskaran ${ }^{4}$, Ming-Cheng Chen ${ }^{5}$, Tsung-Jung $\mathrm{Ho}^{6,7}$, Ray-Jade Chen ${ }^{8}$, Ya-Fang Chen ${ }^{9}$, Viswanadha Vijaya Padma ${ }^{10}$, Ing-Shiow Lay ${ }^{6,7, *}$, Chih-Yang Huang ${ }^{4,6,11, *}$

${ }^{1}$ Department of Occupational Therapy, Asia University, Taichung, Taiwan

${ }^{2}$ Department of Internal Medicine, Cheng Ching Hospital, Taichung, Taiwan

${ }^{3}$ Department of Biological Science and Technology, China Medical University, Taichung, Taiwan

${ }^{4}$ Graduate Institute of Basic Medical Science, China Medical University, Taichung, Taiwan

${ }^{5}$ Division of Colorectal Surgery, Department of Surgery,

Taichung Veterans General Hospital, Taichung, Taiwan

${ }^{6}$ School of Chinese Medicine, College of Chinese Medicine, China Medical University, Taichung, Taiwan

${ }^{7}$ Chinese Medicine Department, China Medical University Beigang Hospital, Yunlin County, Taiwan

${ }^{8}$ Department of Surgery, School of Medicine, College of Medicine,

Taipei Medical University, Taipei, Taiwan

${ }^{9}$ Department of Obstetrics and Gynecology, Taichung Veterans General Hospital, Taichung, Taiwan

${ }^{10}$ Department of Biotechnology, Bharathiar University, Coimbatore, India

${ }^{11}$ Department of Health and Nutrition Biotechnology, Asia University, Taichung, Taiwan

\begin{abstract}
Background: Beta-catenin has been implicated in cell-cell communication in a wide variety of developmental and physiological processes. Defective Wnt signaling could result in various cardiac and vascular abnormalities. Little is known regarding Wnt/frizzled pathway in cardiomyocyte apoptosis.

Methods: In this study, the role of $\beta$-catenin in apoptosis was investigated in H9c2 cardiomyocytes and primary cardiomyocytes isolated in diabetic Wistar rats. The cardiomyocytes were transfected with porcine cytomegalovirus ( $p C M V$ )- $\beta$-catenin plasmid in order to overexpress $\beta$-catenin.

Results: The transcription factor displayed a significant nuclear localization in Wistar rats with cardiac hypertension. Transfection of $\beta$-catenin plasmid induced apoptosis and reduced expression of survival pathway markers in cardiomyocytes in a dose-dependent manner. Furthermore, expression of fibrosis protein markers was upregulated by the overexpression.

Conclusions: Taken together, these results revealed that altered Wnt/B-catenin signaling might provoke heart failure. (Cardiol J 2017; 24, 2: 195-205)

Key words: apoptosis, $\beta$-catenin, cardiomyocytes, fibrosis, survival pathway
\end{abstract}

Address for correspondence: Chih-Yang Huang, PhD, Graduate Institute of Basic Medical Science, Graduate Institute of Chinese Medical Science, China Medical University and Hospital, No. 91, Hsueh-Shih Road, Taichung 40402, Taiwan, tel: +886-4-2205-3366 ext. 3313, fax: +886-4-2207-0465, e-mail: cyhuang@mail.cmu.edu.tw

*These authors have equally contributed to this publication.

Received: 28.06.2016 Accepted: 20.09.2016 


\section{Introduction}

In several studies, it was shown that humoral factors secreted by mechanically stressed cardiomyocytes activate a vast network of intra- and intercellular transduction signals that act in an autocrine or paracrine fashion. These factors are able to alter myocardial ultrastructure and determine cardiac fibroblast hypertrophy and/or apoptosis, mesenchymal fibrotic, inflammatory processes and can alter cardiac gene expression [1-5]. This series of events is the basis of myocardial remodeling [6], which is a complex phenomenon of ultrastructural cardiac rearrangement. Because of the sensible changes in cardiomyocyte viability, energy metabolism and kinetic and electrical properties, as well as in cytoskeletal and extracellular matrix composition, myocardial remodeling is considered a key pathogenetic factor of chronic heart failure and of its natural history, which is marked by inexorable, progressive cardiac dysfunction [7-9].

Cardiac hypertrophy is a fundamental process of adaptation to an increased workload due to hemodynamic overload [10-12]. Development of cardiac hypertrophy is a compensatory response because it augments the number of contractile units and reduces ventricular wall stress to normal levels in accordance with Laplace's Law. Prolonged myocardial hypertrophy triggered by chronic overload may damage the heart over time. Increased ventricular wall thickness initially reduces parietal stress, oxygen requirement and increases heart contractility. However, this compensatory effect is markedly curbed by subsequent expression of pro-apoptotic embryo-fetal genes and fibroblastic hyperplasia with increased collagen synthesis caused by the same biochemical mediators which determine hypertrophy. Loss of contractile tissue due to cardiomyocyte apoptosis and mesenchymal fibrosis is determined by increased collagen synthesis, causingthe heart to dilate and stiffen, which results in systolic and diastolic dysfunction [13].

Beta-catenin has been implicated in cell-cell communication in a wide variety of developmental and physiological processes. Wnt $/ \beta$-catenin signaling is required for different aspects of cardiac and vascular developments. Defective Wnt signaling can result in various cardiac and vascular abnormalities. In the adult heart and blood vessels, activity of the signaling pathway is quite low under normal conditions. However, it is reactivated during pathological cardiac remodeling induced by pressure overload to injured arteries and after myocardial infarction [14].
In recent years, $\beta$-catenin signaling has been clearly shown to be involved in hypertrophic growth [15]. In contrast, little is known regarding Wnt/frizzled pathway in cardiomyocyte apoptosis. In other mammalian cell types, overexpression of $\beta$-catenin promotes apoptosis [16-18]. In a previous study, it was demonstrated that $\beta$-catenin was increased in cardiomyocytes of spontaneously hypertensive heart failure in rats compared with an age-matched control group [19]. In another study, it was indicated that when heart injury occurs, Wnt signaling activates and induces cardiac fibrosis [20]. Moreover, transfection with $\beta$-catenin-specific small interfering RNA or expression of dominant-negative $\mathrm{T}$ cell factor inhibited apoptosis, whereas expression of dominant stable $\beta$-catenin caused significant apoptosis in human ovarian surface epithelial cells [21]. Similar results were also obtained in human $\mathrm{T} / \mathrm{C} 28 \mathrm{a}$ cell line [22], indicating pro-apoptotic roles for $\beta$-catenin and $\mathrm{T}$ cell factor.

Wnt/frizzled pathway is known to be involved in fibrosis of several organ systems (lungs, kidneys and liver) [23-26]. WNT1 and WNT10B are upregulated in pulmonary fibrosis and in liver cirrhosis [23]. In cardiomyocytes, cardiac fibroblasts are regulated in vitro by Wnt signaling cascade [27]. Specific combinations of Wnt ligands and frizzled elicit distinct responses. In vivo, pediatric heart allographs with diastolic dysfunction and severe epicardial fibrosis display nuclear $\beta$-catenin accumulation in fibroblasts, suggesting activation of Wnt signaling [28].

The present study aims to investigate the role of $\beta$-catenin in apoptosis, fibrosis and survival in cardiomyocytes.

\section{Methods}

\section{Human cardiovascular tissue microarray}

Tissue microarray used in this study was purchased from Provitro (Berlin, Germany) comprises heart specimens of normal tissue $(n=10)$ and myocardial scar tissue $(n=10)$. These tissues were collected from females and males with an age range of 25-84 years old. Infarct locations included anterior, posterior and septal segments. Normal tissues included both left and right ventricles. Only the former was used for analysis.

The study procedures conformed to the ethical guidelines of the 1975 Declaration of Helsinki and were reviewed and approved by the Institutional Review Board of the Armed Force Taichung General Hospital, Taichung and the China Medical University, Taichung, Republic of China. Verbal and written informed consents for inclusion in the study were obtained prior to sample collection. 


\section{Diabetic rat model}

Male Wistar rats of 6 weeks old were obtained from the National Laboratory Animal Center, Taiwan. Ambient temperature was maintained at $25^{\circ} \mathrm{C}$ and the animals were kept on an artificial 12-h lightdark cycle. The rats were provided with standard laboratory chow (PMI Nutrition International Inc., Brentwood, MO, USA) and water ad libitum.

Streptozotocin (STZ) was previously shown to induce diabetes in rats [29-32]; therefore, it was administered in the animal model. All animals were acclimatized to the lab conditions for 1 week after their arrival prior to the experiment. All rats were randomly assigned into two groups, i.e., control group and STZ group. STZ group were injected with intraperitoneal injection of STZ $(65 \mathrm{mg} / \mathrm{kg}$ body weight in citrate buffer [pH 4.5]), and control ones were injected with an equal volume of vehicle. Rats which were considered diabetic displayed fasting glucose levels at $>11.1 \mathrm{mM}$ or $>200 \mathrm{mg} / \mathrm{dL}$ at $48 \mathrm{~h}$ after STZ injection, these were detected with AccuSoft test strips (Roche Diagnostics GmbH, Mannheim, Germany).

\section{Immunohistochemistry}

Tissue biopsies from human patients described in the Human Cardiovascular Tissue Microarray section were gathered and fixed with $10 \%$ buffered formalin for 1 overnight, embedded in paraffin and sectioned to $4 \mu \mathrm{m}$-thick fractions. The tissue biopsy samples were dried at $58^{\circ} \mathrm{C}$ overnight and then dewaxed in xylene for $40 \mathrm{~min}$ and rehydrated using graded series of ethanol solutions. Endogenous peroxidase activity was blocked by incubating in hydrogen peroxide blocking buffer $\left(3 \% \mathrm{H}_{2} \mathrm{O}_{2}\right)$ for $13 \mathrm{~min}$. After the samples were rinsed in tap water for $15 \mathrm{~min}$, the microarray biopsies were microwavetreated with pre-warmed citrate buffer $(0.01 \mathrm{M}$ citric acid [pH 6.0]) for $15 \mathrm{~min}$ and then cooled down to room temperature (RT) for $30 \mathrm{~min}$. Nonspecific binding was blocked with $5 \%$ cosmic calf serum (CCS; HyClone Laboratories Inc., South Logan, UT, USA) for $1 \mathrm{~h}$ and then incubated with primary antibody directed against $\beta$-catenin (1:100 dilution; Santa Cruz Biotechnology Inc., TX, USA) at RT for 1 overnight. Then, the samples were incubated with anti-mouse horseradish peroxidase (HRP) secondary antibody (1:100 dilution; Santa Cruz Biotechnology Inc., Dallas, TX, USA) at RT for $1 \mathrm{~h}$. Immunoreactivity was visualized following incubation with 3,3'-diaminobenzidine (DAB) substrate (Roche Diagnostics GmbH, Mannheim, Germany) for $5 \mathrm{~min}$. After the samples were washed with $1 \times$ phosphate-buffered saline $(1 \times$ PBS; GIBCO,
Auckland, New Zealand) for $10 \mathrm{~min}$, the microarray was observed under a microscope (magnification: $200 \times$ ) (Olympus, Tokyo, Japan).

\section{Tissue extraction}

Diabetic Wistar rat tissue samples were homogenized for protein extraction in lysis buffer (20 mM Tris-base [pH 7.4], 2 mM EDTA, $50 \mathrm{mM}$ $\beta$-mercaptoethanol and protease inhibitor tablets) at a concentration of $100 \mathrm{mg}$ tissue/mL buffer. The homogenates were placed on ice for $10 \mathrm{~min}$ and then centrifuged at $13000 \mathrm{~g}$ for $40 \mathrm{~min}$. The supernatants were collected separately and stored at $-80^{\circ} \mathrm{C}$ for further analysis.

\section{Cell culture}

$\mathrm{H} 9 \mathrm{c} 2$ cardiomyoblasts were purchased from American Type Culture Collection (ATCC) (Manassas, VA, USA) and were cultured in $100-\mathrm{mm}$ dishes in Dulbecco's modified Eagle's medium (DMEM; Sigma, St. Louis, MO, USA) supplemented with $10 \%$ CCS in humidified air $\left(5 \% \mathrm{CO}_{2}\right)$ at $37^{\circ} \mathrm{C}$. Cell culture medium was replaced $48 \mathrm{~h}$ after each sub-cultivation. About $3.5 \mathrm{~mL}$ PBS was used to wash each culture plate or vessel. H9c2 cells were transfected with $\beta$-catenin plasmid in a time-dependent and dose-dependent manner.

\section{Transient transfection}

Cells at 50\% confluency were placed in a fresh culture medium containing serum $2 \mathrm{~h}$ before transfection. Then $\mathrm{pCMV}-\beta$-catenin plasmid was transfected into the cells for $24 \mathrm{~h}$ with PureFection $^{\mathrm{TM}}$ Nanotechnology-based Transfection Reagent (System Biosciences, Palo Alto, CA, USA) following the manufacturer protocol. In each experiment, efficiency of gene overexpression was measured by western blot analysis.

\section{Neonatal rat primary cardiomyocyte culture}

Primary cadiomyocytes were isolated from diabetic Wistar rats with Neonatal Rat/Mouse Cardiomyocyte Isolation System Kit (Cellutron Life Technology, Baltimore, MD, USA). Each 10-cm plate was coated with $4 \mathrm{~mL}$ SureCoat solution (Cellutron Life Technology, Baltimore, MD, USA) for $2 \mathrm{~h}$ in humidified air with $5 \% \mathrm{CO}_{2}$ at $37^{\circ} \mathrm{C}$. Hearts of diabetic Wistar rats were isolated and incubated in digestion solution at $37^{\circ} \mathrm{C}$. Each plate was coated with extra $5 \mathrm{~mL}$ SureCoat for $2 \mathrm{~h}$ in humidified air with $5 \% \mathrm{CO}_{2}$ at $37^{\circ} \mathrm{C}$. Then all isolated cells were rested in non-coating dishes for $1 \mathrm{~h}$, heart fibroblasts were seeded to the bottom of each plate 
and floating cells were primary cadiomyocytes, which were subsequently transferred to pre-coated plates. Finally, ventricular cardiomyocytes were cultured in DMEM containing 10\% CCS. After $3-4$ days, the cells were transfected with $\beta$-catenin plasmid in a dose-dependent treatment.

\section{Annexin V-FITC/PI staining}

H9c2 cells were seeded at a density of $2 \times 10^{5}$ cells per $30-\mathrm{mm}$ culture dish and allowed to grow to $60-70 \%$ confluency. Then, $\mathrm{H} 9 \mathrm{c} 2$ cells were transfected with a dose-dependent $\mathrm{pCMV} \beta$-catenin plasmid for $24 \mathrm{~h}$. Apoptotic cells were monitored with a FACSCanto flow cytometer (BD Pharmingen Inc., San Diego, CA, USA) and an Annexin V-FITC Apoptosis Detection Kit (BioVision Inc., Milpitas, CA, USA). Total cells and supernatants were collected, washed and incubated for $15 \mathrm{~min}$ with $1 \times$ binding buffer containing annexin V-conjugated fluorescein isothiocyanate and propidium iodide (PI). Annexin V-FITC staining was used to detect phosphatidylserine (PS) exposure at the cell membrane. Cells that have lost membrane integrity were stained by PI. Annexin V-positive cells were considered early apoptotic cells. Annexin V-and PI-positive cells were considered late apoptosis or necrotic cells, whereas viable cells were unstained.

\section{Western blot analysis}

After the treatment cells were re-suspended in lysis buffer (50 mM Tris-base [pH 7.5], $0.5 \mathrm{M} \mathrm{NaCl}$, $1 \mathrm{mM} \beta$-mercaptoethanol, $1 \% \mathrm{NP}-40,1 \%$ glycerol and protease inhibitor tablets). Samples containing equal amounts of total protein $(40 \mu \mathrm{g})$ were separated by $10 \%$ SDS-PAGE and then transferred onto polyvinylidene difluoride membranes (Millipore Corp., Billerica, MA, USA). Residual protein sites were blocked in $1 \times$ Tween-20/Tris-buffered saline $(1 \times$ TBS $)$ containing $5 \%$ skim milk. Then, the membranes were incubated with 1:1000 diluted primary antibody solutions in $1 \times$ TBS buffer at $4^{\circ} \mathrm{C}$ for at least 1 overnight, depending affinity of each antibody. After the primary antibody solutions were recycled, blots were incubated with secondary antibody solutions $1 \times$ TBS for $1 \mathrm{~h}$.

Primary antibodies against $\beta$-actin, $\mathrm{p}$-Akt, Bax, $\beta$-catenin, caspase- 3 , caspase- 9 , COL2A1, CTGF, cytochrome C, p-IGF1R, MMP2, MMP9, p-PI3K, p-Smad2/3, SP1, TIMP-1, TIMP-2, tPA and uPA were purchased from Santa Cruz Biotechnology (Dallas, TX, USA). Primary antibody against insulin-like growth factor-1 (IGF-1) was purchased from Abcam Plc. (Cambridge, United Kingdom). Secondary antibodies used in this study (anti-goat-
HRP, anti-mouse-HRP and anti-rabbit-HRP) were purchased from Santa Cruz Biotechnology (Dallas, TX, USA).

\section{Assay of MMP2 and MMP9 activities by gelatin zymography}

Activities of MMP2 and MMP9 were assessed by gelatin zymography. After neonatal cardiac fibroblasts were treated with the $\mathrm{pCMV} \beta$-catenin plasmid in a dose-dependent manner, cell-conditioned media were collected. $20 \mu \mathrm{L}$ of each sample was mixed with $5 \mu \mathrm{L}$ loading dye (10\% SDS, $0.5 \mathrm{M}$ Tris- $\mathrm{HCl}[\mathrm{pH} 6.8$ ], $50 \%$ glycerol, $6.25 \mathrm{~g}$ bromophenol blue). The resulting mixtures were loaded to $8 \%$ SDS-PAGE gels containing $0.1 \%$ gelatin and run at $120 \mathrm{~V}$ for $2.5 \mathrm{~h}$. Then, the gels were washed in a $2.5 \%$ Triton X-100 solution with shaking for $30 \mathrm{~min}$ and incubated in $50 \mathrm{~mL}$ reaction buffer (40 mM Tris- $\mathrm{HCl}$ [pH 8.0], $10 \mathrm{mM} \mathrm{CaCl}_{2}$, and $0.01 \%$ $\mathrm{NaN}_{3}$ ) at $37^{\circ} \mathrm{C}$ overnight before staining with $0.25 \%$ Coomassie brilliant blue R-250 in 50\% methanol and $10 \%$ acetic acid for $1 \mathrm{~h}$. Quantitative analysis was performed after the gels were washed twice in a destaining solution (10\% acetic acid, $20 \%$ methanol) for $30 \mathrm{~min}$.

\section{Statistical analysis}

Experimental data in this study were given as the mean \pm standard deviation. Two differences in the groups were compared and analyzed by Student t-test. To analyze differences in multiple groups one-way ANOVA was used and $\mathrm{p}<0.05$ was considered significant.

\section{Results}

Expression patterns of $\beta$-catenin in human infarct hearts and disease model hearts

Expression of $\beta$-catenin protein in human infarct hearts and in diseased animal model hearts were detected. Immunohistochemical staining patterns in myocardial infarction specimens from the cardiovascular tissue microarray were examined. The results showed that $\beta$-catenin staining increased and condensed around the increased interstitial space in the myocardial scar tissue (Fig. 1A). In previous studies, the authors observed cardiac fibrosis and apoptosis in a diabetic animal model $[19,31]$. In addition, $\beta$-catenin protein expression in diseased animal models was determined. $\beta$-catenin protein expression was elevated in diabetic rat hearts (Fig. 1B). Therefore, $\beta$-catenin pathway was elevated when diabetes is present in Wistar rats and in humans. 


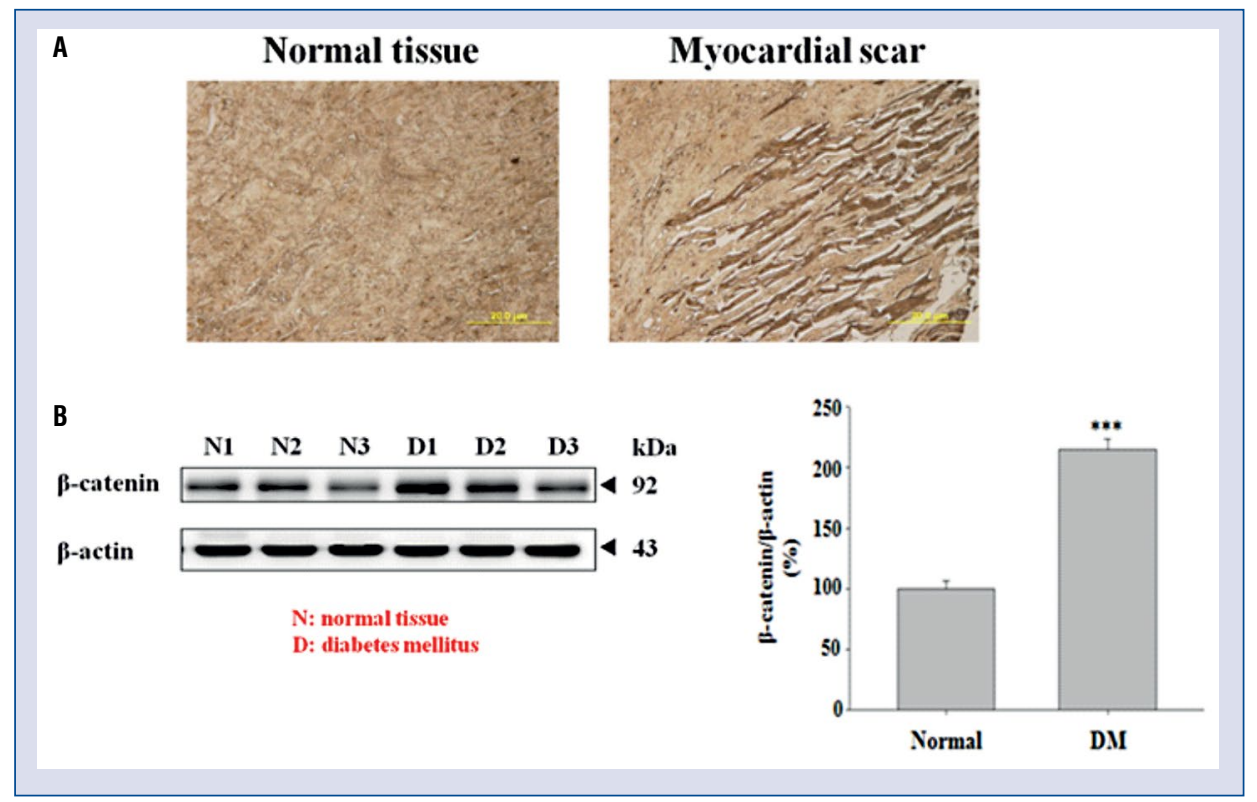

Figure 1. Analysis of $\beta$-catenin expression in left ventricles of human biopsy with myocardial infarction (MI) and diabetic animal model; A. Immunohistochemical analysis of $\beta$-catenin expression in the increased interstitial space in the myocardial scar tissue (brown) from human patients with MI. Left panel: normal tissue. Right panel: myocardial scar tissue. Final magnification: $200 \times$ (scale bar, $200 \mu \mathrm{m}$ ); B. Western blot analysis was conducted to access the $\beta$-catenin expression in heart of diabetic Wistar rats; DM - diabetes mellitus; ${ }^{* *} p<0.001$ vs. normal (increase).

Transfection of a dose- and time-dependent pCMV-beta-catenin plasmid induced cardiomyocyte apoptosis

To determine whether $\beta$-catenin is able to induce apoptosis in cardiomyocytes, flow cytometry and western blot analysis was conducted. When a pCMV- $\beta$-catenin plasmid was transfected in dosedependent and time-dependent manners, expression of apoptosis protein markers Bax, cytochrome c, caspase 3 and caspase 9 showed increased trends in neonatal rat cardiomyocytes and $\mathrm{H} 9 \mathrm{c} 2$ cardiomyoblasts (Fig. 2A, B). Moreover, the percentage of apoptosis was enhanced in the cells transfected with $0.8 \mu \mathrm{g}$ or $1.0 \mu \mathrm{g} \mathrm{pCMV}-\beta$-catenin plasmid (Fig. 2C). Caspase 3 protein expression was increased in $\mathrm{H} 9 \mathrm{c} 2$ cardiomyoblasts transfected with $1.0 \mu \mathrm{g}$ pCMV- $\beta$-catenin (Fig. 2D). Therefore, $\beta$-catenin was capable of inducing apoptosis in cardiomyocytes in dose- and time-dependent manners.

Transfection of a dose- and time-dependent pCMV-beta-catenin plasmid reduces the expression of survival pathway protein markers

To determine whether $\beta$-catenin could reduce the survival of cardiomyocytes, western blot analysis was conducted. When pCMV- $\beta$-catenin plasmid was transfected into $\mathrm{H} 9 \mathrm{c} 2$ and primary neonatal rat car- diomyocytes in dose- and time-dependent manners, expression of the survival pathway protein markers, IGF-1, p-IGF-1R, p-PI3K and p-Akt, were reduced (Fig. 3). Therefore, $\beta$-catenin was able to downregulate IGF-1 pathway and survival in cardiomyocytes.

Transfection of a dose- and time-dependent pCMV-beta-catenin plasmid increased the expression of fibrosis protein markers

Finally, to determine the possibility of inducing fibrosis in cardiomyocytes, gelatin zymography and western blot analyses were conducted. Dosedependent and time-dependent transfection of $\mathrm{pCMV}-\beta$-catenin plasmid upregulate the fibrosis protein markers, CTGF, MMP2, MMP9, p-Smad2/3, SP1, TIMP-1, TIMP-2, tPA and UPA, in both neonatal Wistar rat cardiomyocytes and $\mathrm{H} 9 \mathrm{c} 2$ cardiomyoblasts (Fig. 4A, B). It was found that the expression of the fibrosis protein markers SP1 and collagen II increased in neonatal cardiac fibroblasts alone (Fig. 4C). Conditioned media from the transfection of dose-dependent $\mathrm{pCMV}-\beta$-catenin plasmid into neonatal cardiac fibroblasts were collected and gelatin zymography was performed to measure activities of MMP2 and MMP9. The transfection of $\mathrm{pCMV}-\beta$ -catenin plasmid caused increased MMP2 and MMP9 activities (Fig. 4D). Therefore, $\beta$-catenin overexpression can also induce fibrosis in cardiomyocytes. 


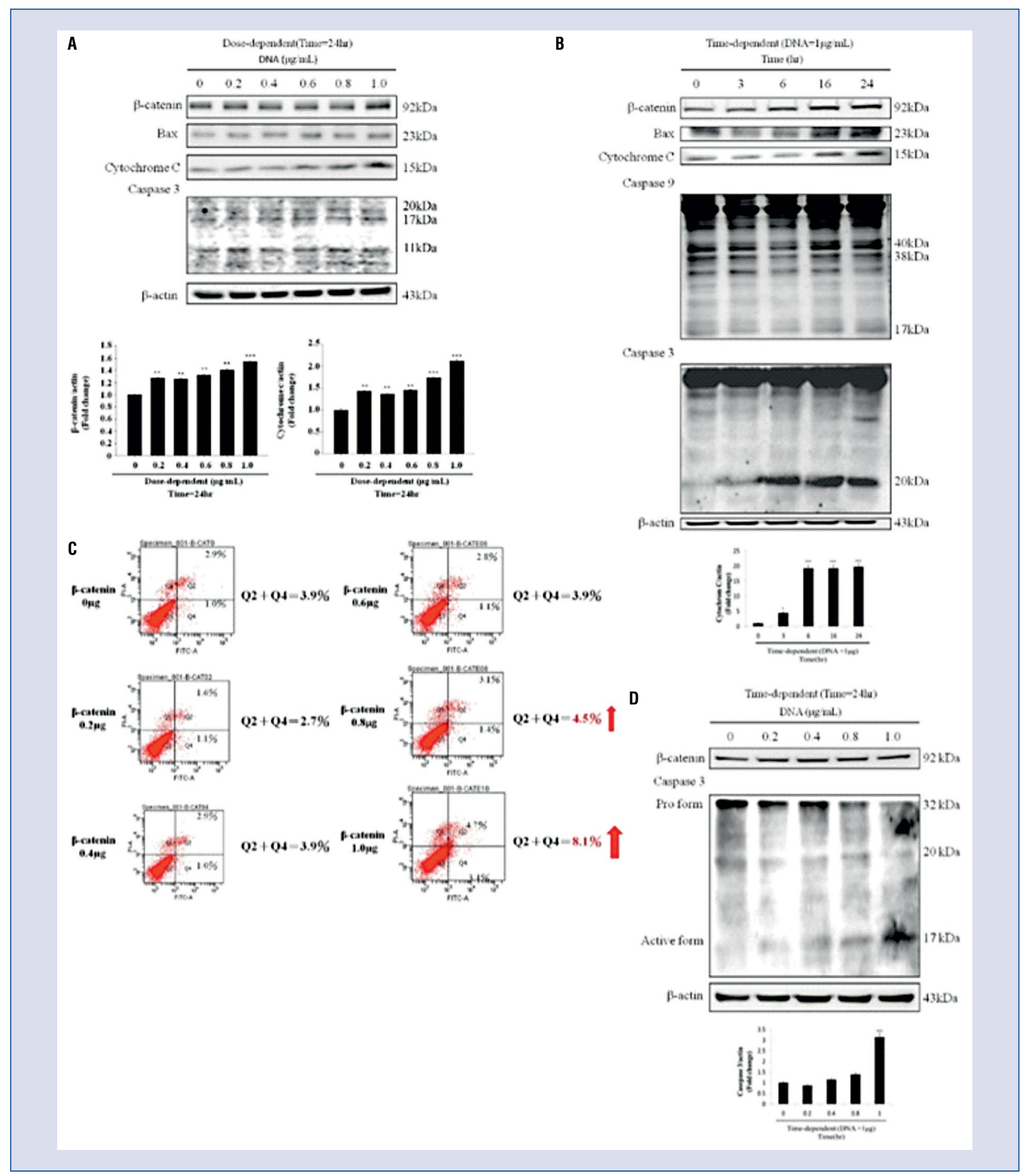

Figure 2. Beta-catenin overexpression induces apoptosis; A. Neonatal rat cardiomyocytes were transfected with $\mathrm{pCMV}-\beta$-catenin for $24 \mathrm{~h}$. Western blot analysis were conducted to investigate effects of dose-dependent $\mathrm{pCMV} \beta$ -catenin plasmid transfection in neonatal rat cardiomyocytes; ${ }^{*} p<0.05 \mathrm{vs}$. control (increase); ${ }^{* *} p<0.01 \mathrm{vs}$. control (increase); ${ }^{* *} \mathrm{p}<0.001$ vs. control (increase); B. H9c2 cells were transfected with a $1 \mu \mathrm{g} / \mathrm{mL} \mathrm{pCMV} \beta$-catenin plasmid for a time-dependent course. Western blot analysis of effects on time-dependent $\mathrm{pCMV} \beta$-catenin plasmid transfection in neonatal rat cardiomyocytes; ${ }^{*} p<0.05$ vs. control (increase); ${ }^{* *} p<0.001$ vs. control (increase); C. H9c2 cells were transfected with a dose-dependent $\mathrm{pCMV} \beta$-catenin plasmid for $24 \mathrm{~h}$. Flow cytometric analysis of apoptotic cells stained by annexin V-FITC in the $\mathrm{x}$-axis and by $\mathrm{PI}$ in the $\mathrm{y}$-axis. The Q4 percentile represents the cells in early apoptosis and the Q2 percentile represents the cells in late apoptosis and/or necrosis. Representative apoptotic percentiles of Q2 plus Q4 are shown; D. H9c2 cells were transfected with a dose-dependent pCMV $\beta$-catenin plasmid for 24 h. Western blot analysis of caspase 3 expression was conducted; ${ }^{* *} p<0.001 \mathrm{vs}$. control (increase). 


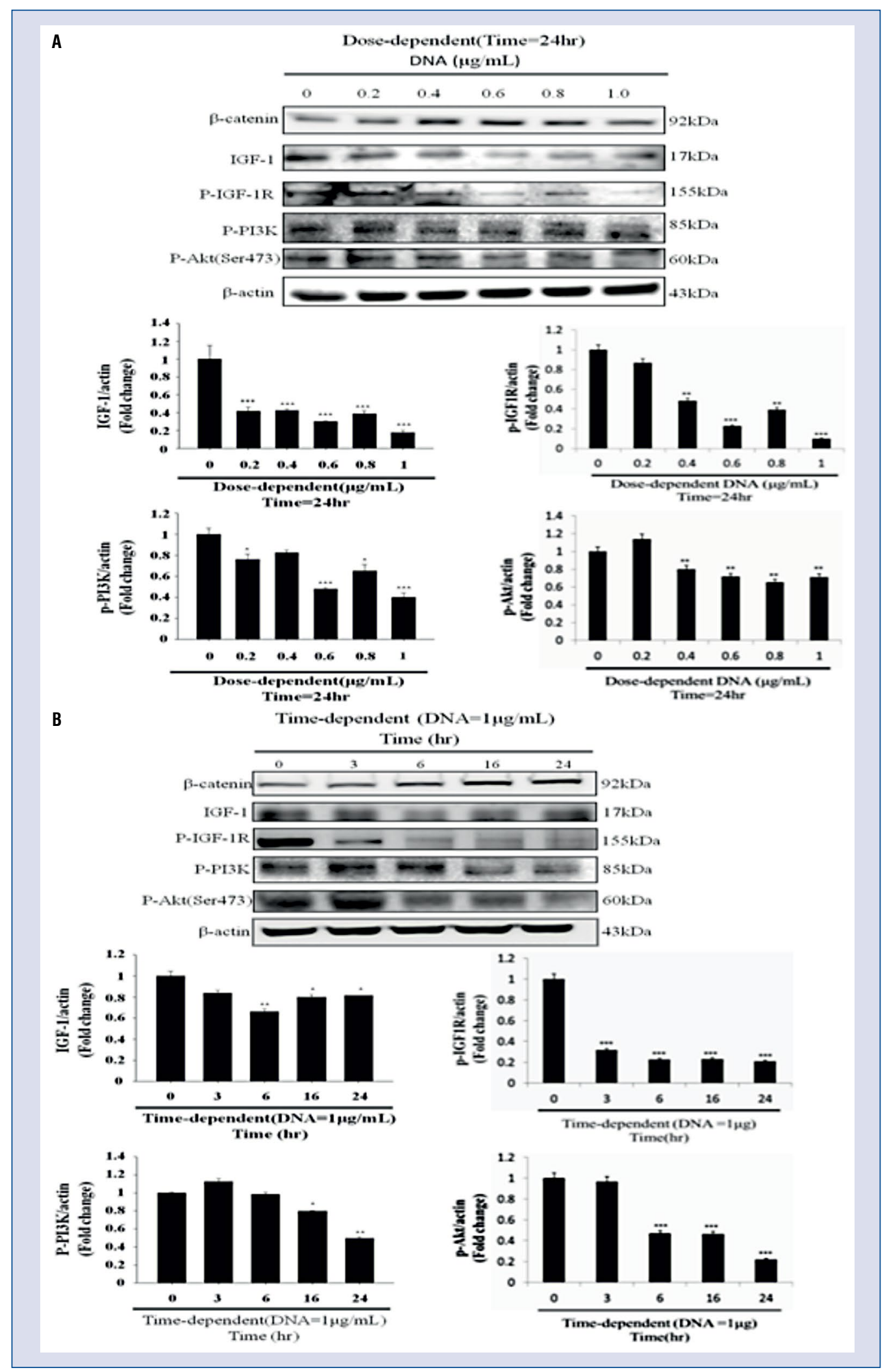

Figure 3. Beta-catenin overexpression decreased the expression of survival pathway protein markers; $\mathbf{A}$. Neonatal rat cardiomyocytes were transfected with a dose-dependent $\mathrm{pCMV} \beta$-catenin plasmid for $24 \mathrm{~h}$. Western blot analysis was conducted to access effect of $\beta$-catenin overexpression on survival pathway; ${ }^{*} \mathrm{p}<0.05 \mathrm{vs}$. control (decrease); ${ }^{* *} \mathrm{p}<0.01$ vs. control (decrease); ${ }^{* *} \mathrm{p}<0.001$ vs. control (decrease); B. H9c2 cells were transfected with $1 \mu \mathrm{g} / \mathrm{mL} \mathrm{pCMV} \beta$ -catenin plasmid for a time-dependent course. After transfection, the expression of survival protein markers was accessed by western blot analysis; ${ }^{*} p<0.05$ vs. control (decrease); ${ }^{* *} p<0.01$ vs. control (decrease); ${ }^{* *} p<0.001$ vs. control (decrease). 


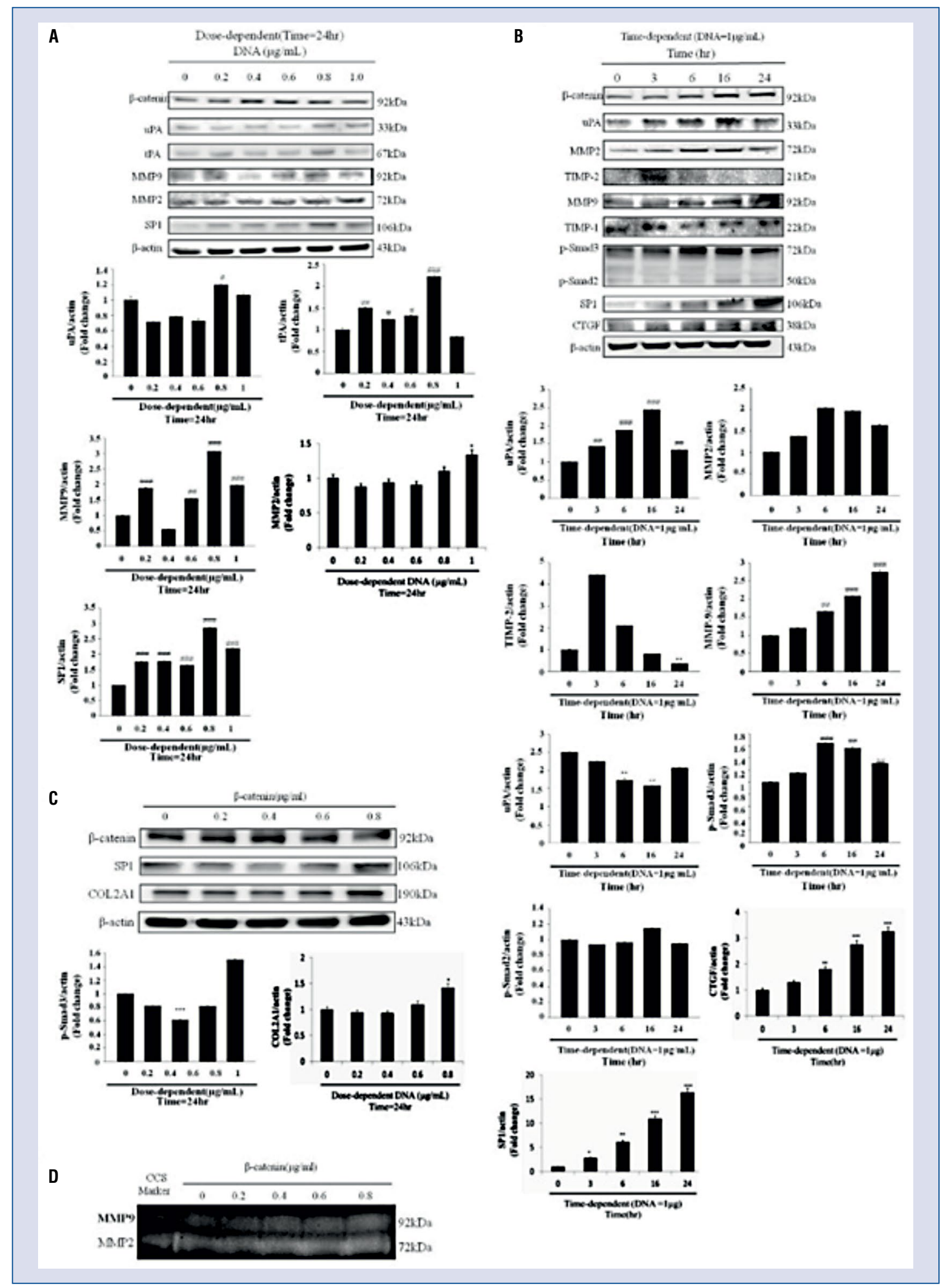

Figure 4. Beta-catenin overexpression increased the expression of fibrosis protein markers and decreased the expression of TIMP-2 and TIMP-1; A. Neonatal rat cardiomyocytes were transfected with a dose-dependent pCMV $\beta$-catenin plasmid for $24 \mathrm{~h}$; ${ }^{*} \mathrm{p}<0.05$ vs. control (increase); B. H9c2 cells were transfected with a $1 \mu \mathrm{g} / \mathrm{mL} \mathrm{pCMV} \beta$-catenin plasmid in a time-dependent manner. After transfection, expression of fibrosis protein markers were accessed by western blot analysis; ${ }^{*} p<0.05$ vs. control (increase); ${ }^{* *} p<0.01 \mathrm{vs}$. control (increase); ${ }^{* *} p<0.001 \mathrm{vs}$. control (increase); C, D. Neonatal cardiac fibroblasts were transfected with a dose-dependent pCMV $\beta$-catenin plasmid for $24 \mathrm{~h}$. After transfection, the cells were collected and conditioned media were harvested. Western blot analysis and gelatin zymography were conducted to access effects of $\mathrm{pCMV} \beta$-catenin plasmid on fibrosis; ${ }^{*} \mathrm{p}<0.05$ vs. control (increase). 


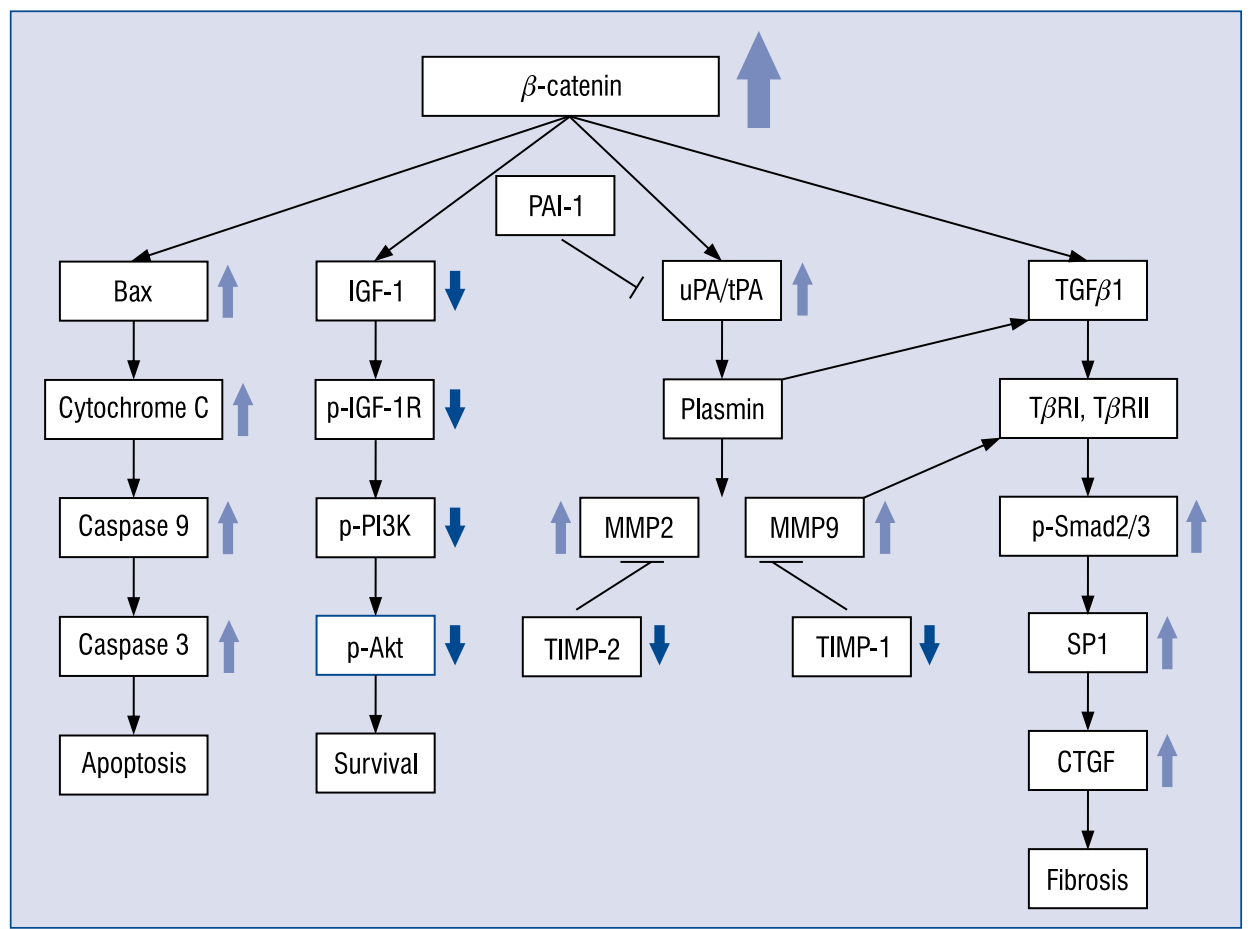

Figure 5. Beta-catenin over-expression induces apoptosis and fibrosis by down regulating survival in cardiomyocytes.

\section{Discussion}

Certain humoral factors secreted by mechanically stressed cardiomyocytes activate a vast network of intra- and intercellular transduction signals that lead to cardiac dysfunctions [1-5]. Although such abnormalities can be compensated by cardiac hypertrophy, which is a fundamental process of adaptation to an increased workload due to hemodynamic overload [10-12], loss of contractile tissue, cardiomyocyte apoptosis and mesenchymal fibrosis will eventually occur [13]. Beta-catenin signaling is activated during pathological cardiac remodeling induced by pressure overload in injured arteries and after myocardial infarction [14]. In addition, it was found to induce apoptosis in other mammalian cell types [16-18], heart failure in rats [19] and cardiac fibrosis [20]. However, the role of $\beta$-catenin in apoptosis, fibrosis and survival in cardiomyocytes requires further study.

Factors that may trigger cardiomyocyte apoptosis include mechanical forces, oxidative stress and hypoxia as well as an unbalanced presence of growth factors and cytokines or neurotransmitters $[33,34]$. $\mathrm{Wnt} / \beta$-catenin signaling is known to be required for different aspects of cardiac and vascular development. Defective Wnt signaling can result in various cardiac and vascular abnormalities. Moreover, in other studies, it was indicated that Wnt signaling is involved in cardiovascular diseases coupled with ion channels and cardiac hypertrophy $[35,36]$. In the present study, $\beta$-catenin expression was detected in human infarct hearts and in diseased animal model hearts. The results showed that $\beta$-catenin protein expression increased and condensed around the interstitial space in the myocardial scar tissue. In addition, expression levels of the transcription factor $\beta$-catenin was found to be increased in diabetic rat hearts. Thus, $\beta$-catenin might play a crucial role in apoptosis induction in cardiomyocytes. Expression of apoptosis markers (Bax, cytochrome c, caspase 3 and caspase 9) was upregulated after transfection of $\mathrm{pCMV}-\beta$-catenin plasmid in neonatal rat cardiomyocytes and $\mathrm{H} 9 \mathrm{c} 2$ cardiomyoblasts. Moreover, the apoptosis level was found to be elevated by transfection with $\mathrm{pCMV}-\beta$-catenin plasmid.

In a recent review, it was reported that transforming growth factor beta 3 (TGF $\beta 3$ ) could induce fibrosis through Smad and/or $\beta$-catenin signaling and addressed the role of apoptosis in fibrosis [37]. Arrhythmogenic right ventricular dysplasia/ cardiomyopathy (ARVD/C) is an inherited cardiac arrhythmia originating in the right ventricle and results in heart failure and sudden cardiac death. Development of ARVD/C type 1 has been attributed to differential expression of TGF $\beta 3$. TGF $\beta 3$ 
overexpression could have an activating role in $\mathrm{Wnt} / \beta$-catenin pathway. In human renal proximal tubular cells, TGFBR2 was shown to dissociate from adherent junctions upon TGF $\beta 1$ activation [38]. TGF $\beta 3$ is also known to bind to the same receptor, possibly eliciting a similar process in the heart. Incubation with TGF $\beta 1$ yielded increased levels of $\beta$-catenin and dissociation of $\beta$-catenin from adherent junction complexes was observed previously [39]. In addition, cytoplasmic $\beta$-catenin was stabilized by TGF $\beta$ activity, thereby promoting $\mathrm{Wnt} / \beta$-catenin signaling $[38,39]$. Transfection with $\mathrm{pCMV}-\beta$-catenin plasmid increased fibrosis markers (uPA, tPA, MMP2, MMP9) in neonatal rat cardiomyocytes and in $\mathrm{H} 9 \mathrm{c} 2$ cardiomyoblasts. In addition, expression of fibrosis markers SP1 and collagen II increased in neonatal cardiac fibroblasts alone. Taken together, these demonstrated that $\mathrm{Wnt} / \beta$-catenin pathway could be necessary for TGF $\beta$-induced fibrosis in cardiomyocytes $[23,24]$.

Transforming growth factor $\beta$ signaling has also been implicated in both cell growth and apoptosis, depending on the concentration of the cytokine and on the signaling context. Myocardial cells of patients suffering from $\mathrm{ARVD} / \mathrm{C}$ were shown to express and overexpress proapoptotic caspase 3 and Bax, respectively $[40,41]$. In different studies, hypoxia was shown to induce $\mathrm{TGF} \beta$ activity [42-44]. In addition, activities of $\beta$-catenin and TGF $\beta$ were shown to be co-related [45-47].

\section{Conclusions}

In conclusion, $\mathrm{Wnt} / \beta$-catenin signaling cascade is capable of damaging cardiomyocytes and this study will provide a clear picture in treatment of cardiovascular disease. Strategies of targeting $\beta$-catenin expression in cardiomyocytes assists in preventing heart cells from myocardial infarctioninduced apoptosis, fibrosis and reduced survival.

\section{Highlights}

1. Diabetes mellitus caused increased $\beta$-catenin expression in humans and Wistar rats.

2. Beta-catenin overexpression led to increased apoptosis in $\mathrm{H} 9 \mathrm{c} 2$ cardiomyoblasts.

3. Beta-catenin resulted in reduced $\mathrm{H} 9 \mathrm{c} 2$ cell survival.

4. Overexpression of $\beta$-catenin up-regulated fibrosis markers in $\mathrm{H} 9 \mathrm{c} 2$ cardiomyoblasts.

\section{Acknowledgments}

This study is supported in part by the Taiwan Ministry of Health and Welfare Clinical Trial and Research Center of Excellence (MOHW105-TDU-B-212-133019).

\section{Conflict of interest: None declared}

\section{References}

1. Huang CY, Lee SD. Possible pathophysiology of heart failure in obesity: Cardiac apoptosis. BioMedicine. 2012; 2(1): 36-40, doi: 10.1016/j.biomed.2011.12.004.

2. Messaoudi S, Azibani F, Delcayre C, et al. Aldosterone, mineralocorticoid receptor, and heart failure. Mol Cell Endocrinol. 2012; 350(2): 266-272, doi: 10.1016/j.mce.2011.06.038, indexed in Pubmed: 21784127.

3. Soltysinska E, Olesen SP, Osadchii OE. Myocardial structural, contractile and electrophysiological changes in the guinea-pig heart failure model induced by chronic sympathetic activation. Exp Physiol. 2011; 96(7): 647-663, doi: 10.1113/expphysiol.2011.058503, indexed in Pubmed: 21571815.

4. Talan MI, Ahmet I, Xiao RP, et al. $\beta_{2}$ AR agonists in treatment of chronic heart failure: long path to translation. J Mol Cell Cardiol. 2011; 51(4): 529-533, doi: 10.1016/j.yjmcc.2010.09.019, indexed in Pubmed: 20888833.

5. Yin WH, Chen YH, Wei J, et al. Associations between endothelin-1 and adiponectin in chronic heart failure. Cardiology. 2011; 118(4): 207-216, doi: 10.1159/000328780, indexed in Pubmed: 21701170.

6. Distefano G, Sciacca P. Molecular pathogenesis of myocardial remodeling and new potential therapeutic targets in chronic heart failure. Ital J Pediatr. 2012; 38: 41, doi: 10.1186/1824-7288-38-41, indexed in Pubmed: 22971785.

7. Lin WY, Liu HP, Chang JS, et al. Genetic variations within the PSORS1 region affect Kawasaki disease development and coronary artery aneurysm formation. BioMedicine. 2013; 3(2): 7381, doi: 10.1016/j.biomed.2013.03.001.

8. Palomeque J, Delbridge L, Petroff MV. Angiotensin II: a regulator of cardiomyocyte function and survival. Front Biosci (Landmark Ed). 2009; 14: 5118-5133, indexed in Pubmed: 19482608.

9. Shah AM, Mann DL. In search of new therapeutic targets and strategies for heart failure: recent advances in basic science. Lancet. 2011; 378(9792): 704-712, doi: 10.1016/S01406736(11)60894-5, indexed in Pubmed: 21856484.

10. Cooper G. Cardiocyte adaptation to chronically altered load. Annu Rev Physiol. 1987; 49: 501-518, doi: 10.1146/annurev. ph.49.030187.002441, indexed in Pubmed: 2952050.

11. Mondry A, Swynghedauw B. Biological adaptation of the myocardium to chronic mechanical overload. Molecular determinants of the autonomic nervous system. Eur Heart J. 1995; 16 Suppl I: 64-73, indexed in Pubmed: 8829959.

12. Ruwhof C, van der Laarse A. Mechanical stress-induced cardiac hypertrophy: mechanisms and signal transduction pathways. Cardiovasc Res. 2000; 47(1): 23-37, indexed in Pubmed: 10869527.

13. Diwan A, Dorn GW. Decompensation of cardiac hypertrophy: cellular mechanisms and novel therapeutic targets. Physiology (Bethesda). 2007; 22: 56-64, doi: 10.1152/physiol.00033.2006, indexed in Pubmed: 17289931.

14. van de Schans VAM, Smits JFM, Blankesteijn WM. The Wnt/frizzled pathway in cardiovascular development and disease: friend or foe? Eur J Pharmacol. 2008; 585(2-3): 338-345, doi: 10.1016/j. ejphar.2008.02.093, indexed in Pubmed: 18417121. 
15. ter Horst P, Smits JFM, Blankesteijn WM. The Wnt/Frizzled pathway as a therapeutic target for cardiac hypertrophy: where do we stand? Acta Physiol (Oxf). 2012; 204(1): 110 -117, doi: 10.1111/j.1748-1716.2011.02309.x, indexed in Pubmed: 21624093

16. Kim K, Pang KM, Evans M, et al. Overexpression of beta-catenin induces apoptosis independent of its transactivation function with LEF-1 or the involvement of major G1 cell cycle regulators. Mol Biol Cell. 2000; 11(10): 3509-3523, indexed in Pubmed: 11029052.

17. Olmeda D, Castel S, Vilaró S, et al. Beta-catenin regulation during the cell cycle: implications in G2/M and apoptosis. Mol Biol Cell. 2003; 14(7): 2844-2860, doi: 10.1091/mbc.E03-01-0865, indexed in Pubmed: 12857869.

18. Zhang Z, Deb A, Zhang Z, et al. Secreted frizzled related protein 2 protects cells from apoptosis by blocking the effect of canonical Wnt3a. J Mol Cell Cardiol. 2009; 46(3): 370-377, doi: 10.1016/j. yjmcc.2008.11.016, indexed in Pubmed: 19109969.

19. Zheng Q, Chen P, Xu Z, et al. Expression and redistribution of $\beta$-catenin in the cardiac myocytes of left ventricle of spontaneously hypertensive rat. J Mol Histol. 2013; 44(5): 565-573, doi: 10.1007/s10735-013-9507-6, indexed in Pubmed: 23591738.

20. Deb A. Cell-cell interaction in the heart via Wnt $/ \beta$-catenin pathway after cardiac injury. Cardiovasc Res. 2014; 102(2): 214-223, doi: 10.1093/cvr/cvu054, indexed in Pubmed: 24591151.

21. Pon YL, Wong AST. Gonadotropin-induced apoptosis in human ovarian surface epithelial cells is associated with cyclooxygenase-2 up-regulation via the beta-catenin/T-cell factor signaling pathway. Mol Endocrinol. 2006; 20(12): 3336-3350, doi: 10.1210/ me.2006-0125, indexed in Pubmed: 16945989.

22. Jüllig M, Zhang WV, Ferreira A, et al. MG132 induced apoptosis is associated with p53-independent induction of pro-apoptotic Noxa and transcriptional activity of beta-catenin. Apoptosis. 2006; 11(4): 627-641, doi: 10.1007/s10495-006-4990-9, indexed in Pubmed: 16673057.

23. Akhmetshina A, Palumbo K, Dees $\mathrm{C}$, et al. Activation of canonical Wnt signalling is required for TGF- $\beta$-mediated fibrosis. Nat Commun. 2012; 3: 735, doi: 10.1038/ncomms1734, indexed in Pubmed: 22415826.

24. Dawson K, Aflaki M, Nattel S. Role of the Wnt-Frizzled system in cardiac pathophysiology: a rapidly developing, poorly understood area with enormous potential. J Physiol. 2013; 591(6): 1409-1432, doi: 10.1113/jphysiol.2012.235382, indexed in Pubmed: 23207593.

25. Henderson WR, Chi EY, Ye X, et al. Inhibition of Wnt/beta-catenin/ CREB binding protein (CBP) signaling reverses pulmonary fibrosis. Proc Natl Acad Sci U S A. 2010; 107(32): 14309-14314, doi: 10.1073/pnas.1001520107, indexed in Pubmed: 20660310.

26. He W, Dai C, Li Y, et al. Wnt/beta-catenin signaling promotes renal interstitial fibrosis. J Am Soc Nephrol. 2009; 20(4): 765-776, doi: 10.1681/ASN.2008060566, indexed in Pubmed: 19297557.

27. Laeremans H, Rensen SS, Ottenheijm HCJ, et al. Wnt/frizzled signalling modulates the migration and differentiation of immortalized cardiac fibroblasts. Cardiovasc Res. 2010; 87(3): 514-523, doi: 10.1093/cvr/cvq067, indexed in Pubmed: 20189955.

28. Ye Bo, Ge Y, Perens G, et al. Canonical Wnt $/ \beta$-catenin signaling in epicardial fibrosis of failed pediatric heart allografts with diastolic dysfunction. Cardiovasc Pathol. 2013; 22(1): 54-57, doi: 10.1016/j. carpath.2012.03.004, indexed in Pubmed: 22475572.

29. Guo Z, Xia Z, Yuen VG, et al. Cardiac expression of adiponectin and its receptors in streptozotocin-induced diabetic rats. Metabolism. 2007; 56(10): 1363-1371, doi: 10.1016/j.metabol.2007.05.005, indexed in Pubmed: 17884446.

30. Kanter M, Aksu F, Takir M, et al. Effects of Low Intensity Exercise Against Apoptosis and Oxidative Stress in Streptozotocininduced Diabetic Rat Heart. Exp Clin Endocrinol Diabetes. 2016 [Epub ahead of print], doi: 10.1055/s-0035-1569332, indexed in Pubmed: 26824288.
31. Wu KK, Huan YM. Streptozotocin-induced diabetic models in mice and rats. . Curr Protoc Pharmacol. 2008: 5.47.1-5.47.14.

32. Liu X, Liu C, Li J, et al. Urocortin attenuates myocardial fibrosis in diabetic rats via the Akt/GSK-3 $\beta$ signaling pathway. Endocr Res. 2016; 41(2): 148-157, doi: 10.3109/07435800.2015.1094489, indexed in Pubmed: 26934363.

33. Diez J, Fortuno MA, Ravassa S. Apoptosis in hypertensive heart disease. Curr Opin Cardiol. 1998; 130: 317-325.

34. Fortuño MA, Ravassa S, Fortuño A, et al. Cardiomyocyte apoptotic cell death in arterial hypertension: mechanisms and potential management. Hypertension. 2001; 38(6): 1406-1412, indexed in Pubmed: 11751726.

35. Flaherty M, Dawn B. Noncanonical Wnt11 signaling and cardiomyogenic differentiation. Trends Cardiovasc Med. 2008; 18(7): 260-268, doi: 10.1016/j.tcm.2008.12.001.

36. Pandey S. Targeting Wnt-Frizzled signaling in cardiovascular diseases. Mol Biol Rep. 2013; 40(10): 6011-6018, doi: 10.1007/ s11033-013-2710-4, indexed in Pubmed: 24057182.

37. Vanderschuren KLA, Sieverink T, Wilders R. Arrhythmogenic right ventricular dysplasia/cardiomyopathy type 1: a light on molecular mechanisms. Genet Res Int. 2013; 2013: 460805, doi: 10.1155/2013/460805, indexed in Pubmed: 24416594.

38. Tian YC, Phillips AO. Interaction between the transforming growth factor-beta type II receptor/Smad pathway and beta-catenin during transforming growth factor-beta1-mediated adherens junction disassembly. Am J Pathol. 2002; 160(5): 1619-1628, indexed in Pubmed: 12000714.

39. Guo Y, Xiao L, Sun L, et al. Wnt/beta-catenin signaling: a promising new target for fibrosis diseases. Physiol Res. 2012; 61(4): 337-346, indexed in Pubmed: 22670697.

40. Mallat Z, Tedgui A, Fontaliran F, et al. Evidence of apoptosis in arrhythmogenic right ventricular dysplasia. N Engl J Med. 1996; 335(16): 1190-1196, doi: 10.1056/NEJM199610173351604, indexed in Pubmed: 8815941.

41. Yamaji K, Fujimoto S, Ikeda Y, et al. Apoptotic myocardial cell death in the setting of arrhythmogenic right ventricular cardiomyopathy. Acta Cardiol. 2005; 60(5): 465-470, doi: 10.2143/ AC.60.5.2004965, indexed in Pubmed: 16261775.

42. Hanna C, Hubchak SC, Liang X, et al. Hypoxia-inducible factor$2 \alpha$ and TGF- $\beta$ signaling interact to promote normoxic glomerular fibrogenesis. Am J Physiol Renal Physiol. 2013; 305(9): F1323-F1331, doi: 10.1152/ajprenal.00155.2013, indexed in Pubmed: 23946285.

43. Hung SP, Yang MH, Tseng KF, et al. Hypoxia-induced secretion of TGF- $\beta 1$ in mesenchymal stem cell promotes breast cancer cell progression. Cell Transplant. 2013; 22(10): 1869-1882, doi: 10.3727/096368912X657954, indexed in Pubmed: 23067574.

44. Suzuki YJ. Cell signaling pathways for the regulation of GATA4 transcription factor: Implications for cell growth and apoptosis. Cell Signal. 2011; 23(7): 1094-1099, doi: 10.1016/j.cellsig.2011.02.007, indexed in Pubmed: 21376121.

45. Jian H, Shen X, Liu I, et al. Smad3-dependent nuclear translocation of beta-catenin is required for TGF-beta1-induced proliferation of bone marrow-derived adult human mesenchymal stem cells. Genes Dev. 2006; 20(6): 666-674, doi: 10.1101/ gad.1388806, indexed in Pubmed: 16543220.

46. Zhou B, Liu Y, Kahn M, et al. Interactions between $\beta$-catenin and transforming growth factor- $\beta$ signaling pathways mediate epithelial-mesenchymal transition and are dependent on the transcriptional co-activator cAMP-response element-binding protein (CREB)-binding protein (CBP). J Biol Chem. 2012; 287(10): 7026-7038, doi: 10.1074/jbc.M111.276311, indexed in Pubmed: 22241478 .

47. Zhou S. TGF- $\beta$ regulates $\beta$-catenin signaling and osteoblast differentiation in human mesenchymal stem cells. J Cell Biochem. 2011; 112(6): 1651-1660, doi: 10.1002/jcb.23079, indexed in Pubmed: 21344492 